Research Article

\title{
Corrosion Crack Nucleation Mechanism in the Welded Structures of X65 Steel in Natural Seawater
}

\author{
Linyue Bai $(\mathbb{D}$, Lei Gao $\mathbb{i}$, and Kebin Jiang \\ Field Engineering Institute, Army Engineering University of PLA, Nanjing 210007, China \\ Correspondence should be addressed to Kebin Jiang; kbjiang1122@sina.com
}

Received 31 January 2018; Accepted 4 July 2018; Published 13 August 2018

Academic Editor: Paolo Ferro

Copyright (c) 2018 Linyue Bai et al. This is an open access article distributed under the Creative Commons Attribution License, which permits unrestricted use, distribution, and reproduction in any medium, provided the original work is properly cited.

\begin{abstract}
The nucleation mechanism of corrosion cracks in welded structures in natural seawater has been revealed through investigation on the corrosion behavior of X65-welded structures in natural seawater. The evolution laws of surface corrosion morphology, residual stress, and areas of welded structures with the most serious corrosion damage were analyzed by microstructure observation, corrosion morphology observation, residual stress detection, and magnetic field detection. The results show that the main factors of determining surface corrosion morphology evolution law of welded structures are microstructures of the weld joint, heat-affected zone (HAZ), and the fusion line. Due to the difference of corrosion rates between the weld joint, HAZ, and the coarse Widmänstatten structure in fusion line, the fusion line of welded structures receives the most serious damage while being corroded. Meanwhile, mutual reinforcement of residual stress and corrosion damage on the surface of welded structures further accelerate the nucleation of corrosion cracks. Under the influences of microstructure, residual stress, and corrosion, corrosion cracks that are parallel to weld joints generate first in the fusion line of welded structures. Therefore, it makes welded structures the source of marine steel structures' corrosion failure.
\end{abstract}

\section{Introduction}

Due to the good connection performance and excellent air tightness, welding fabrication has been applied in the manufacturing of marine steel structures such as drilling platforms and seabed pipelines [1-4]. However, welded structures will always be high-risk areas for the occurrence of corrosion crack in the sea and source of corrosion failure of marine steel structures [5-8]. With international investment increasing in marine projects, corrosion protection of welded structures in the marine environment has been a focus of research [9-12].

In marine environments, embalmment of welded structures is usually done by smearing marine anticorrosive coating [11, 13-15]. However, absorption and osmosis of corrosion factor $\left(\mathrm{Cl}^{-}\right)$still enable it to penetrate protective coating, leading to the generation of corrosion couple on metal surface and coating failure [16, 17]. Therefore, to prevent the occurrence of corrosion failure accidents of welded structures in the marine environment, research on the corrosion crack nucleation mechanism of welded structures in the marine environment needs to be carried out.

With studies and reports on corroded welded structures increasing in recent years, researchers have deeper understandings of corroded welded structures [18-21]. However, the research emphasis is always on the corrosion characteristics of different weld joints $[7,8,20]$, extended behavior of corrosion fatigue crack [22-24], and specific corrosion environment's impacts on corrosion characteristics of welded structures [25-27]. Relatively little research is dedicated to the nucleation mechanism of corrosion cracks in welded structures. Moreover, although theories such as hydrogen-induced cracking and anodic dissolution can reveal the corrosion crack nucleation mechanism of nonwelded structures to some extent [28-31], such traditional theories are not sufficient to reveal the nucleation mechanism of corrosion cracks in welded structures because of the particularities in terms of crystal structure and residual stress distribution of welded structures. 
As an important factor in influencing the corrosion behavior of welded structures, residual stress has obvious impacts on the corroded damaging rate of welded structures [32-35]. However, most reports focus on the impact of residual stress on the corrosion behavior in the research of corroded welded structures, but mutual effects between residual stress and corrosion damages are ignored. The overlook of influence on the surface residual stress distribution of welded structures arising from corrosion morphology changes makes research conclusions inaccurate. Thus, interaction between residual stress and corrosion damage needs to be studied to reveal the nucleation mechanism of corrosion cracks in welded structures.

In this paper, welded structures of X65 steel were studied, and the microstructures of the weld joint, HAZ, and fusion line were observed with an optical microscope. Moreover, residual stress inside the part of the specimens was lowered with vibratory stress relief (VSR) method. Evolution of corrosion morphologies of welded specimens that have different residual stress in natural seawater was observed with scanning electron microscope (SEM), aiming to show the influence of residual stress on the corroded damaging rate of different parts of the welded structure. Blind-hole method was used to detect the evolution law of surface residual stress of the corroded welded specimen. Then, influence of change of surface corrosion morphology on residual stress distribution was obtained, and the interaction between residual stress and corrosion damage was summarized. Additionally, a magnetometer was used to detect magnetic field distribution of welded specimens' surface in the process of corrosion, so as to study evolution law of distribution of areas that received the most serious corrosion damage on the surface of the welded structure. Nucleation mechanism of corrosion cracks in the welded structures in natural seawater was analyzed by synthesis with experimental data.

\section{Materials and Methods}

2.1. Materials and Welding Process. The dimensions of X65 steel-welded specimens were $350 \mathrm{~mm} \times 150 \mathrm{~mm} \times 10 \mathrm{~mm}$ after welding, and the direction of weld joint was parallel to the short edge with length $150 \mathrm{~mm}$. The chemical components of X65 steel are listed in Table 1.

The groove type was $\mathrm{V}$-groove, groove angle was $60^{\circ}$, counterpart gap was $2.5 \mathrm{~mm}$, and truncated edge was $1.5 \mathrm{~mm}$. The weld reinforcement was $1.6 \mathrm{~mm}$, and the cap weld was $1.6 \mathrm{~mm}$ wider than both sides of the groove after welding. The schematic of groove is shown in Figure 1.

All specimens were processed with root welding of cellulose electrode. Furthermore, semiautomatic selfprotection welding with flux-cored wire was utilized in weld beads of filling and covering. Electrode of cellulose type was E6010 and flux-cored wire was E71T8-K6. Welding parameters for each layer of weld are shown in Table 2.

2.2. Seawater Corrosion Test. Seawater corrosion test was finished according to the Chinese national technique
TABLE 1: Chemical components of X65 steel.

\begin{tabular}{lccccccccc}
\hline Elements & $\mathrm{C}$ & $\mathrm{Si}$ & $\mathrm{Mn}$ & $\mathrm{P}$ & $\mathrm{S}$ & $\mathrm{V}$ & $\mathrm{Nb}$ & $\mathrm{Ti}$ & $\mathrm{Fe}$ \\
\hline \multirow{2}{*}{ Wt.\% } & Max & $\operatorname{Max}$ & $\operatorname{Max}$ & $\operatorname{Max}$ & $\operatorname{Max}$ & $\operatorname{Max}$ & $\operatorname{Max}$ & $\mathrm{Max}$ & \multirow{2}{*}{ Bal. } \\
& 0.16 & 0.45 & 1.60 & 0.025 & 0.015 & 0.10 & 0.06 & 0.05 & \\
\hline
\end{tabular}

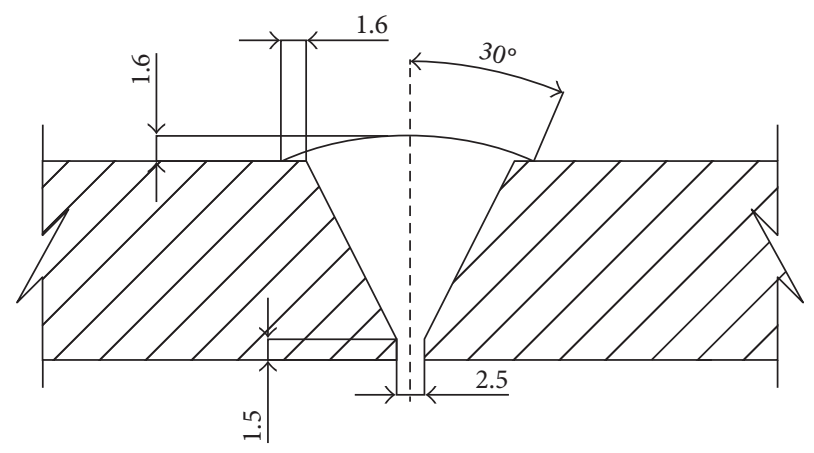

FIGURE 1: Groove schematic.

standard GB/T 6384-2008, with natural seawater from the East China Sea corroding the test specimens. Major chemical components of seawater from the East China Sea are listed in Table 3. While the specimens were immersed in the seawater, distances of $2 \mathrm{~m}$ and $0.8 \mathrm{~m}$ were maintained from the upper surface of seawater and seafloor, respectively. Test specimens were connected with graphite flake through wires to constitute a galvanic cell structure in the experiment, aiming to increase the corrosion rate of the welded specimen. Through comparison of the corrosion rates of specimens with and without graphite flake in 60 days, the specimen-graphite galvanic cell structure was proved to increase the corrosion rate of the specimen by $69.1 \%$. Welded specimens were divided into 8 groups before the test, numbering A1-A8. There were three specimens in each group, numbering A1-1, A1-2,..., A8-2, A8-3. To exclude the effect of difference among specimens' initial surface morphologies on evolution of corrosion morphology of specimens, the surface of each specimen was burnished before corrosion test.

To eliminate the residual stress in specimens of group A1-A4, vibration was imposed by high-speed motor on specimens of group A1-A4 with the VSR method before the corrosion test. The effect of surface residual stress of the welded structure on corroded damaging rates of the weld joint, HAZ, and fusion line was studied through the comparison of differences between surface corrosion morphologies of specimens processed and unprocessed by VSR $[36,37]$. In order to guarantee the residual stress elimination effect of the VSR method, a three-dimensional stress magnetometer of $\mathrm{JH}-80$ was used to detect the surface residual stress of group A1 before and after VSR. The sensitivity coefficient of X65 steel needed to be measured before detection to improve the accuracy of detection results, and the value of X65 steel's sensitivity coefficient was $0.0153 \mathrm{~mA} / \mathrm{MPa}$, which was calculated from measurement results. Limited by the size of specimens, only transversal residual stress whose direction was perpendicular to the weld joint was detected. Detection results showed that the 
TABLE 2: Welding parameters.

\begin{tabular}{|c|c|c|c|c|c|}
\hline Weld bead & $\begin{array}{c}\text { Grades and specifications of welding } \\
\text { consumables (mm) }\end{array}$ & Polarity & $\begin{array}{l}\text { Welding } \\
\text { current }(\mathrm{A})\end{array}$ & Arc voltage $(\mathrm{V})$ & $\begin{array}{l}\text { Welding speed } \\
(\mathrm{cm} / \mathrm{min})\end{array}$ \\
\hline Root welding & E6010, $\varphi 3.2$ & Negative & $60 \sim 90$ & $25 \sim 35$ & $6 \sim 13$ \\
\hline Hot welding & & & $180 \sim 250$ & & $15 \sim 30$ \\
\hline Filling & E71T8-K6, $\varphi 2.0$ & Positive & $160 \sim 240$ & $18 \sim 19$ & $12 \sim 25$ \\
\hline Facing & & & $160 \sim 240$ & & $12 \sim 25$ \\
\hline
\end{tabular}

TABLE 3: Major chemical components of seawater from the East China Sea.

\begin{tabular}{lcccccccc}
\hline Elements & $\mathrm{K}^{+}$ & $\mathrm{Na}^{+}$ & $\mathrm{Mg}^{2+}$ & $\mathrm{Ca}^{2+}$ & $\mathrm{HCO}_{3}{ }^{-}$ & $\mathrm{Cl}^{-}$ & $\mathrm{SO}_{4}{ }^{2-}$ & $\mathrm{SiO}_{2}$ \\
\hline $\mathrm{Mg} / \mathrm{L}$ & 354 & 9854 & 1182 & 385 & 130 & 17742 & 2477 & 0.9 \\
\hline
\end{tabular}

stress peaks of A1-1, A1-2, and A1-3 located in the fusion line were decreased from $115.83,118.96$, and $98.85 \mathrm{MPa}$ to $33.87,29.96$, and $37.92 \mathrm{MPa}$, respectively, after VSR. The residual stress decrease rates of A1-1, A1-2, and A1-3 were $70.76 \%, 74.81 \%$, and $61.64 \%$, respectively, which means that the residual stress elimination effect of VSR method was significant.

After the seawater corrosion test starts, specimens from group A1-A8 were taken out, respectively, on day 60, 120, 180 , and 360 , and corrosion products on the surface were removed by $\mathrm{H}_{2} \mathrm{SO}_{4}$ solution (GB 6384-86, UDC 669: 620.193.1). Additionally, corrosion inhibitor of thiourea was added to protect the base material while pickling. After wiping out corrosion products, corrosion morphology, residual stress distribution, and magnetic field distribution on the surface of specimens were detected and experimental data were collected. The specimens taken at each time node and data needed to be collected in the seawater corrosion test are shown in Table 4.

2.3. Collection of Test Data. The weld joint, HAZ, and fusion line of the welded specimen were each intercepted from an uncorroded welded specimen whose welding process was identical to specimens of group A1-A8, used for the manufacturing of metallographic specimens. After interception, inspected surface size of metallographic specimens was $30 \mathrm{~mm} \times 10 \mathrm{~mm}$ and the height of specimens was $10 \mathrm{~mm}$. Surface treatment of metallographic specimens followed the Chinese national technique standard GB/T13298-2015. After wearing off the specimen's surface, the surface was burnished by a mechanical prototype and polished by a polishing machine. Then, the metal surface was soaked in a mixed solution made from $\mathrm{HNO}_{3}$ and alcohol to show the microstructure. $\mathrm{HNO}_{3}$ accounted for $5 \%$ of the eroded solution and the eroding time was $45 \mathrm{~s}$. After finishing making metallographic specimens, the microstructure on the surface was observed with an optical microscope. Observation of corrosion morphology was finished with SEM. When observed, corrosion morphologies of the corroded specimen's weld joint, HAZ, and fusion line's surface were recorded, respectively. Furthermore, magnetic field
TABLE 4: Date when specimens go out of water and data collection.

\begin{tabular}{|c|c|c|}
\hline $\begin{array}{l}\text { Time } \\
\text { node }\end{array}$ & $\begin{array}{c}\text { Serial number of specimen } \\
\text { out of water }\end{array}$ & Data to be collected \\
\hline $60 \mathrm{~d}$ & Group A1, A5 & 1. Surface corrosion \\
\hline $120 \mathrm{~d}$ & Group A2, A6 & morphology \\
\hline $180 \mathrm{~d}$ & Group A3, A7 & $\begin{array}{l}\text { 2. Distribution of residual } \\
\text { stress }\end{array}$ \\
\hline $360 \mathrm{~d}$ & Group A4, A8 & $\begin{array}{l}\text { 3. Surface magnetic field } \\
\text { distribution }\end{array}$ \\
\hline
\end{tabular}

distribution on the corroded surface of the welded specimen was detected with stress concentration magnetic detector TSC-2M-8 [38]. The magnetic field in the middle area of the corroded specimen's surface, which covers $240 \mathrm{~mm} \times 60 \mathrm{~mm}$, was detected, and the collected data were processed with software MMM-System 3.0. The external magnetic field compensation was open while being measured, and step size $S$ and measured spacing $b$ were $2 \mathrm{~mm}$ and $4 \mathrm{~mm}$, respectively.

Before the detection of residual stress, stress-releasing coefficients of X65 steel in the blind-hole method needed to be measured according to the Chinese national technique standard CB 3395-92, used for the calculation of residual stress. A special drilling device of ZS21B and static strain gauge of DH3820 were used to measure the stress-releasing coefficients, and values of borehole depth and borehole aperture were $1.5 \mathrm{~mm}$ and $2 \mathrm{~mm}$, respectively. The measurement results of stress-releasing coefficients were $A=-0.04882$ and $B=-0.05533$. Instruments and borehole parameters used in the detection of residual stress were identical to that used in the measurement of stress-releasing coefficients, and the detection and calculation of residual stress in the blind-hole method followed the Chinese national technique standard CB 3395-92 as well.

As the corrosion surface of the welded specimen was not flat, the surface of the measured point was polished up with a handheld high-speed grinding head to paste strain flower effectively. Considering that surface polish might have some impacts on the detection results of residual stress, additional strain arising from the grinding operation needed to be measured with tests so that it could be applied to revise the results of residual stress detection. To determine the additional strain, first the high-speed grinder head was used to polish up the surface of a X65 steel plate without internal stress. Then the steel plate's surface, including the polished and unpolished area, was drilled with drilled holes' parameter, which was the same as the one detected from residual stress. Finally, the difference between average value of released strain that passed the grinding position and average 
value of the strain that missed the grinding position was the additional strain caused by grinding. Detection results of grinding additional strain in the direction of $0^{\circ}, 45^{\circ}$, and $90^{\circ}$ were $\varepsilon_{0^{\circ}}=0.076 \mu \mathrm{m}, \varepsilon_{45^{\circ}}=0.003 \mu \mathrm{m}, \varepsilon_{90^{\circ}}=-0.036 \mu \mathrm{m}$.

\section{Results and Discussion}

3.1. Microstructure. Microstructures of the weld joint, HAZ, and fusion line are shown in Figure 2. While being welded, weld joint, whose microstructure is made of granular ferrite, acicular ferrite, and pearlite, is formed through crystal nucleation growth and solidification of welding pool. Large amounts of granular pearlite are distributed in the space between granular ferrite and acicular ferrite, making the microstructure of the weld joint finer (Figure 2(a)). Due to the heat input in the process of the welded structure, crystal expansion and bulk ferrite with large size appear in HAZ. Meanwhile, a small amount of bainite is deposited. Thus, the microstructure on the surface of HAZ is mainly made of granular ferrite, with a small amount of bainite (Figure 2(b)). The volume of metal crystal between base metal and weld joint increases with more heat input absorbed by the base metal besides the fusion line; moreover, temperature gradient changes of metal in the fusion line are greater while cooling, leading to the creation of coarse Widmanstätten at last (Figure 2(c)).

3.2. Corrosion Morphology Evolution. The corrosion morphology observation results of the weld joint, HAZ, and fusion line's surface of specimens in groups A1-A4 and groups A5-A8 were summarized and used for analyzing evolution laws of corrosion morphologies in different areas of welded structures with different residual stress. Different evolution laws of corrosion morphologies on weld joint of welded structures processed and unprocessed by VSR are shown in Figure 3. It is seen from Figure 3 that corrosion damages on the surface of the corroded weld joint processed and unprocessed by VSR worsen as the corrosion time increases. Additionally, corrosion damage on the surface of the weld joint unprocessed by VSR are more severe than the damage of the weld joint processed by VSR, which means that stronger residual stress could make the corrosion damage on the weld joint's surface worse. In the early days of corrosion $(60 \mathrm{~d})$, corrosion morphology on the surface of the weld joint shows characteristics of pitting. As the corrosion time increases, density of corrosion pitting on the surface becomes greater, as does the depth and diameter of the pitting. When the corrosion time reaches $180 \mathrm{~d}$, pitting becomes united and forms continuous corrosion damages. When the corrosion time is $360 \mathrm{~d}$, corrosion damage on the surface of the weld joint enlarges again and becomes a continuous corrosion pitting with a large diameter. The explanation is that granular ferrite on the surface of the weld joint will be first damaged and forms corrosion pitting while being corroded, but acicular ferrite and granular pearlite regions enjoy strong corrosion resistance. Thus, there is relatively little corrosion damage. Although stronger residual stress on the surface of the weld joint unprocessed by VSR could increase the depth and diameter of pitting, corrosion morphologies of the weld joint's surface are still mainly corrosive pitting in the evolution.

Evolution of corrosion morphology on the surface of HAZ is shown in Figure 4. After being processed by VSR, corrosion morphology on the surface of HAZ changes from pitting to uniform corrosion as the time increases. However, it could not fully turn itself into uniform corrosion (Figure 4(a)). Furthermore, corrosion morphology on the surface of HAZ unprocessed by VSR has been turned into uniform corrosion when the corrosion time is $180 \mathrm{~d}$. When the corrosion time reaches $360 \mathrm{~d}$, both corrosion pits with large aperture and continuous corrosion damage appear on HAZ's surface again (Figure 4(b)). It is seen that corrosion morphologies on the surface of HAZ are interchangeable between pitting and uniform corrosion. Additionally, the stronger the residual stress on the HAZ's surface is, the faster the reciprocal conversion rate between pitting and uniform corrosion will be. Corrosion damaging rate of HAZ's surface will be faster too.

While analyzing the microstructure of HAZ, bulk granular ferrite on HAZ's surface will be destroyed at first while being corroded and a large-aperture pit appears. Then, further corrosion occurs in other regions with bainite shedding and leads to the uniform corrosion morphology on the surface of HAZ. When corrosion separation appears on surface metal, the procedure mentioned above is repeated on the surface of HAZ and interchangeable pitting and uniform corrosion occurs.

Evolution of corrosion morphology in the fusion line is shown in Figure 5. After the welded structure is corroded, apparent corrosion grooves appear in the fusion line. On one hand, the generation of corrosion grooves results from the difference of corrosion rates between the weld joint and HAZ near the fusion line. On the other hand, the coarse Widmänstatten (Figure 2(c)) structure weakens the corrosion resistance of metal in the fusion line and further accelerates propagation rate in depth of corrosion grooves. Meanwhile, the longer the corrosion time is, the deeper the corrosion grooves in the fusion line are.

To study the influence of residual stress on the rising rate of corrosion groove depth, four parts of corrosion grooves in each specimen were cut randomly (cutting direction is vertical to weld joint) and the depth of each cutting groove was measured. Thus, evolution law of corrosion groove depth in the welded structure with corrosion time increases was obtained by calculating the average depth value of measured corrosion grooves in each specimen group. Both the welded structures processed and unprocessed by VSR are studied, and average depth evolution laws of grooves are shown in Figure 6. The findings show deeper corrosion grooves that are formed in the fusion line of specimens unprocessed by VSR. However, as corrosion products continue to gather around corrosion grooves, an increasing rate of corrosion depth goes down with corrosion time increases. Depth difference between corrosion grooves in the fusion line unprocessed and processed by VSR is widened. When the corrosion time is $60 \mathrm{~d}, 120 \mathrm{~d}, 180 \mathrm{~d}$, and $360 \mathrm{~d}$, the difference value of the grooves' depth in the fusion line 

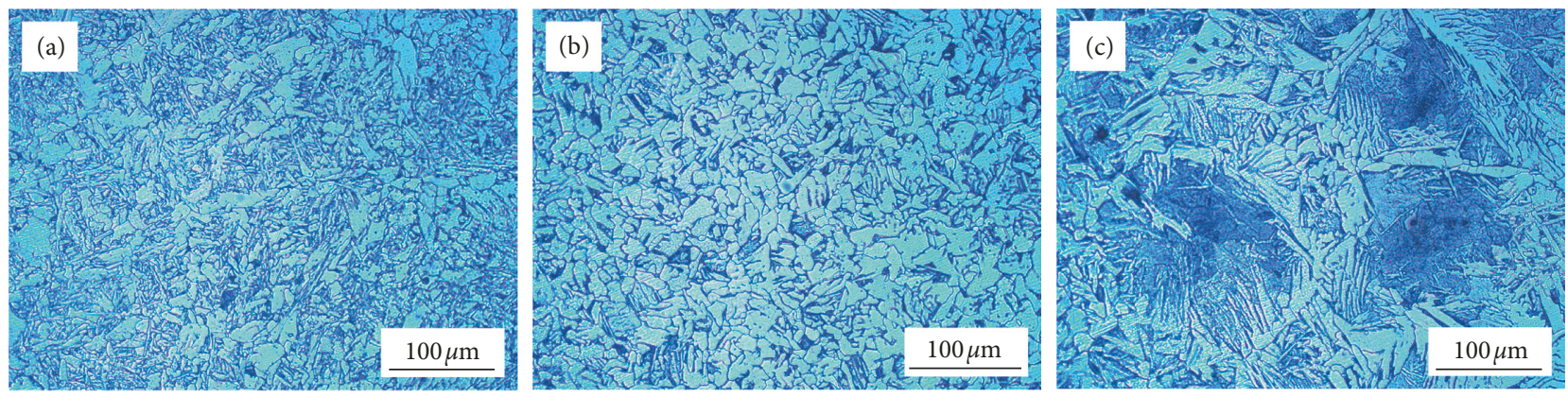

Figure 2: Microstructure in different areas of welded structure. (a) Weld joint. (b) HAZ. (c) Fusion line.
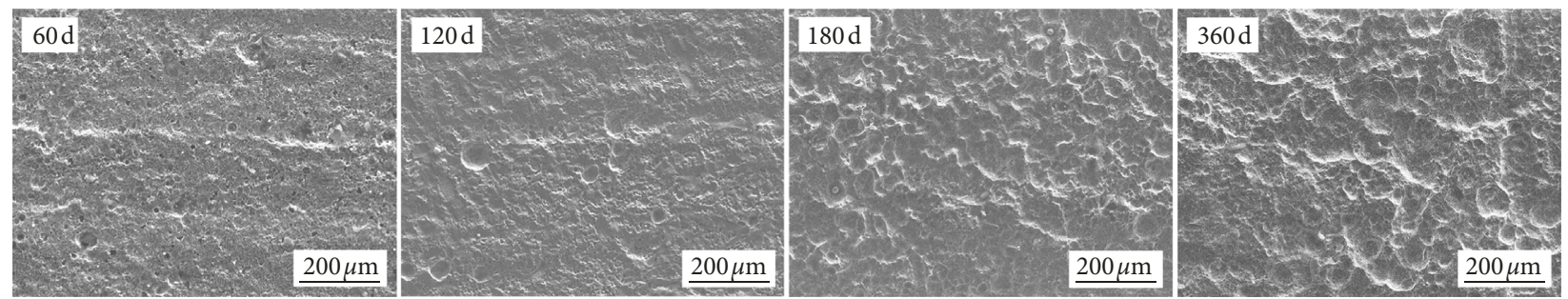

(a)
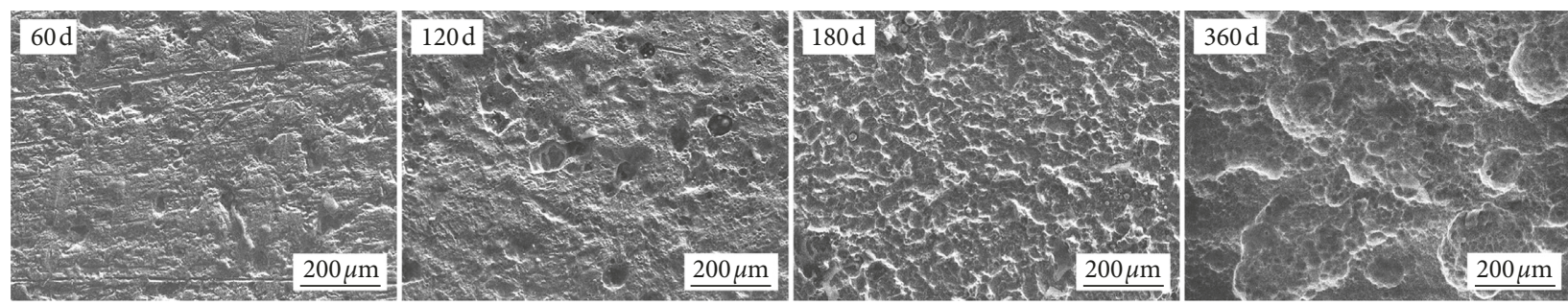

(b)

FIGURE 3: Evolution of corrosion morphology on weld joint's surface. (a) Weld joint processed by VSR. (b) Weld joint unprocessed by VSR.
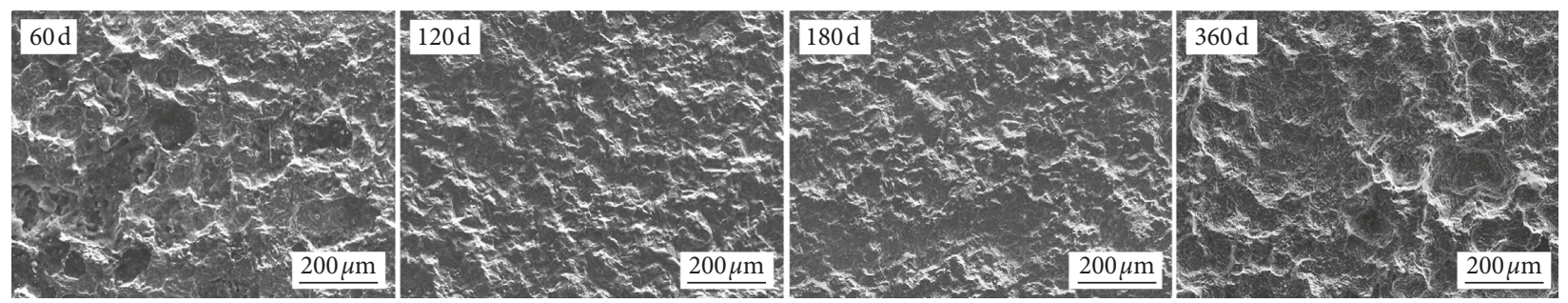

(a)
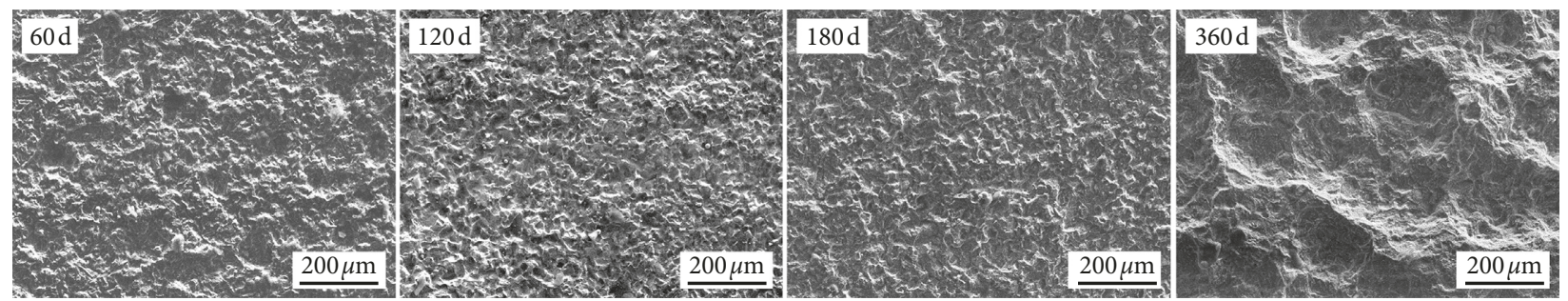

(b)

FIGURE 4: Evolution of corrosion morphology on HAZ's surface. (a) HAZ processed by VSR. (b) HAZ unprocessed by VSR. 

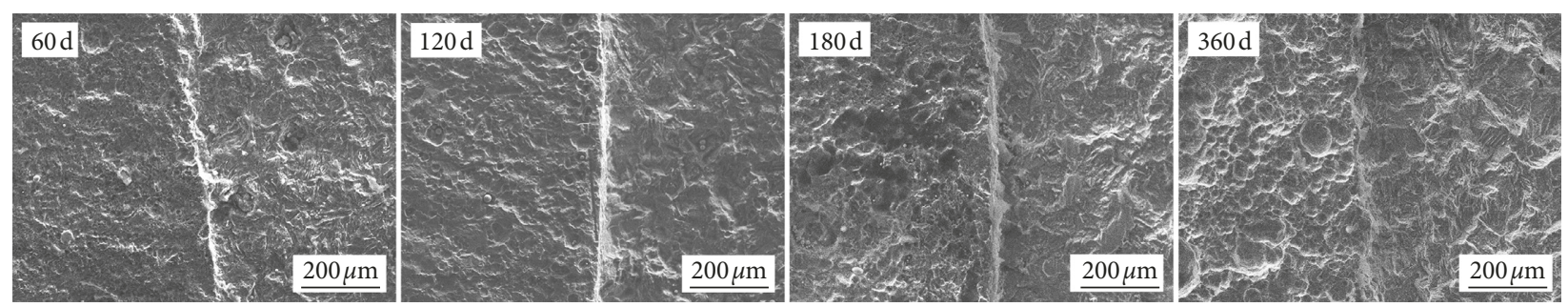

(a)
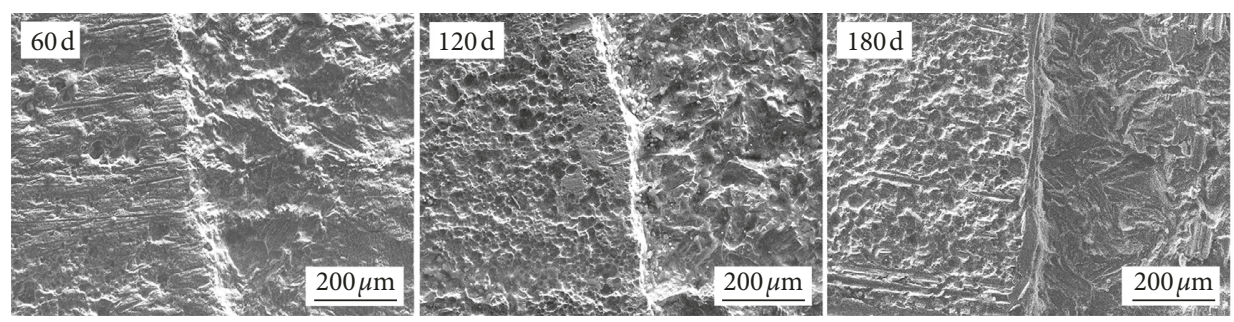

(b)

FIgURE 5: Evolution of corrosion morphology in the fusion line. (a) Fusion line processed by VSR. (b) Fusion line unprocessed by VSR.

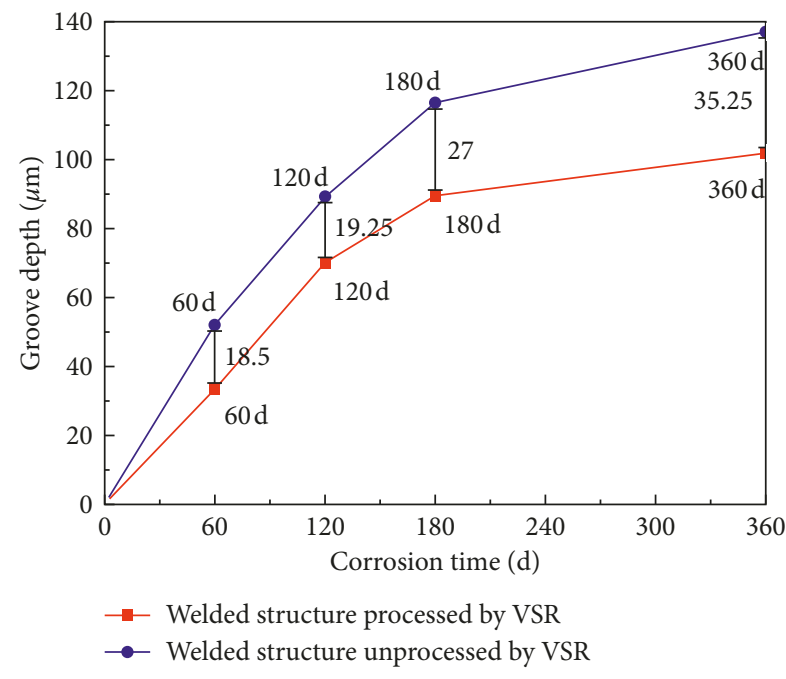

Figure 6: Changes of corrosion groove depth.

unprocessed and processed by VSR in each corrosion time is $18.5 \mu \mathrm{m}, 19.25 \mu \mathrm{m}, 27 \mu \mathrm{m}$, and $35.25 \mu \mathrm{m}$, respectively. Thus, it shows that residual stress in the fusion line plays an increasingly important role in contributing to the depth development of corrosion grooves while the welded structure is being corroded.

3.3. Residual Stress Evolution. After detecting residual stress, the average value of surface residual stress detection results of three corroded specimens in each group is referred to as the analysis data of residual stress. Thus, evolution laws of surface transverse residual stress distribution of welded structures are shown in Figure 7. In the early days of corrosion $(60 \mathrm{~d})$, transverse residual stress on the surface of the welded structure first increases as it gets farther from the fusion line, then the stress decreases. The peak point of stress is $20 \mathrm{~mm}$ from the fusion line. However, transverse residual stress in the fusion line becomes greater as the corrosion time increases. When the corrosion time is $360 \mathrm{~d}$, the value of transverse residual stress in the fusion line of the welded structure unprocessed by VSR is greater than the value of transverse stress that is $20 \mathrm{~mm}$ from the fusion line, and the value of transverse residual stress in the fusion line becomes the peak point of residual stress. On the other hand, whether the welded structure enjoys VSR or not, an increasing rate of transverse residual stress in the fusion line decreases as corrosion time increases. The reason is that the corroded damaging rate in the fusion line decreases as corrosion time increases while the welded structure is being corroded.

The evolution law of longitudinal residual stress whose direction is parallel to the weld joint is shown in Figure 8. While being corroded, evolution laws of longitudinal residual stress distribution of welded structures processed and unprocessed by VSR are generally the same, and peak values of longitudinal residual stress on welded structures' surface are both in the fusion line. Furthermore, as it becomes farther from the fusion line, longitudinal residual tensile stress on the surface of the welded structure turns to residual compressive stresses swiftly. Finally, it gradually approaches the zero line. While being corroded, longitudinal residual stress in the fusion line increases with corrosion time growing. Furthermore, increasing rate of longitudinal residual stress in the fusion line slows down. However, longitudinal residual stress shows no obvious laws as corrosion time increases in the area $20 \mathrm{~mm}$ away from the fusion line.

By the contrast between Figures 7 and 8, transverse and longitudinal residual stress on the surface of the welded structure processed by VSR is obviously weaker than that on the surface of the welded structure unprocessed by VSR. However, transverse and longitudinal residual stress in the fusion line is relatively strong when corrosion time is $360 \mathrm{~d}$. Meanwhile, evolution laws of transverse and longitudinal residual stress in the fusion line are positively related to the 


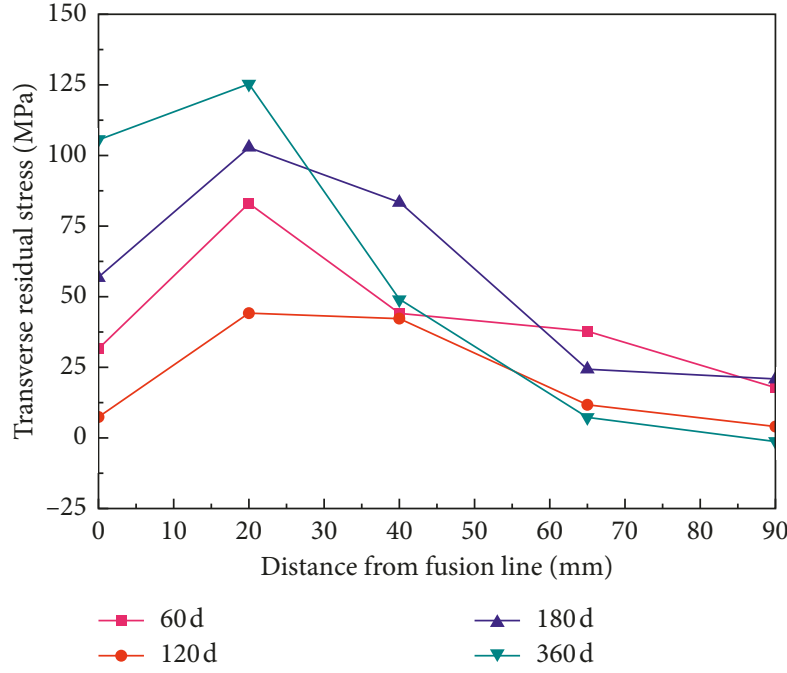

(a)

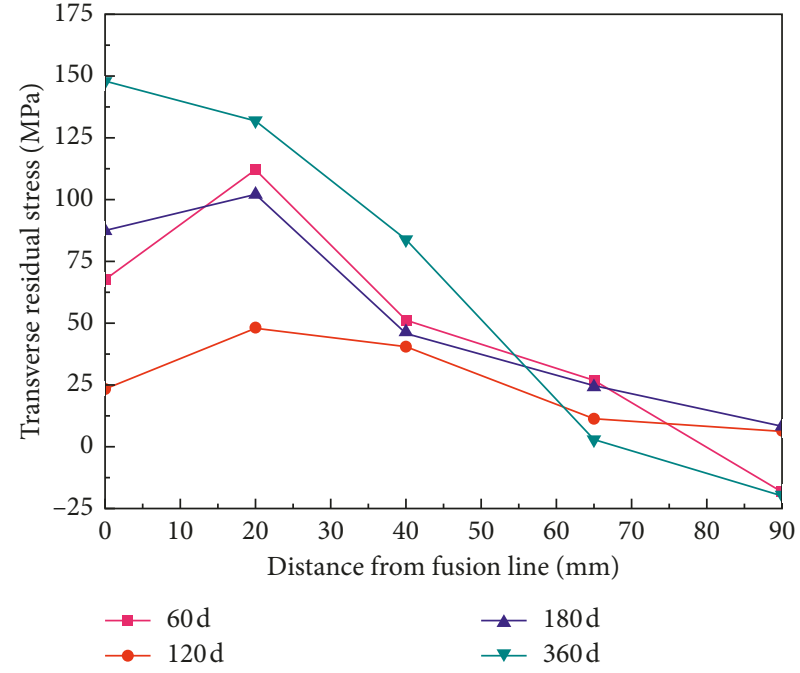

(b)

FIGURE 7: Evolution law of transverse residual stress distribution. (a) Welded structure processed by VSR. (b) Welded structure unprocessed by VSR.

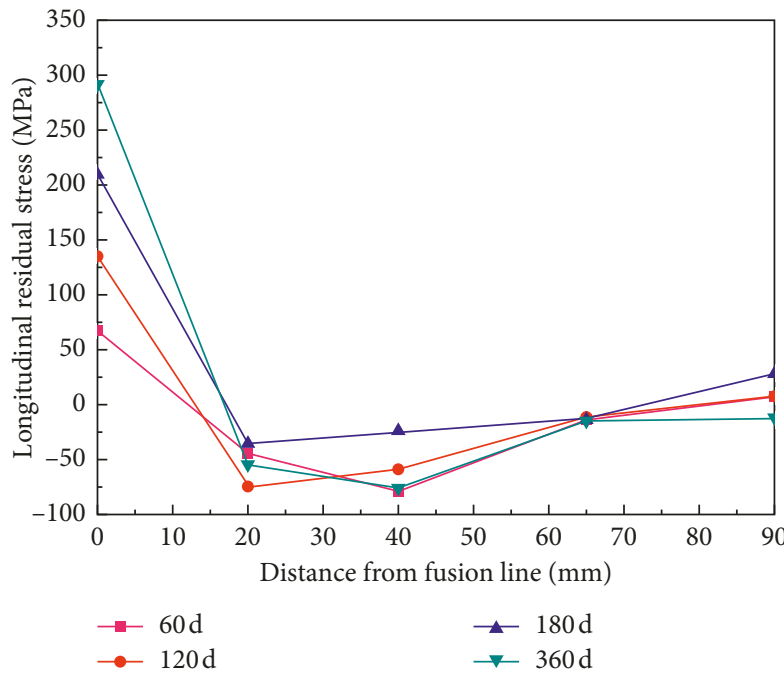

(a)

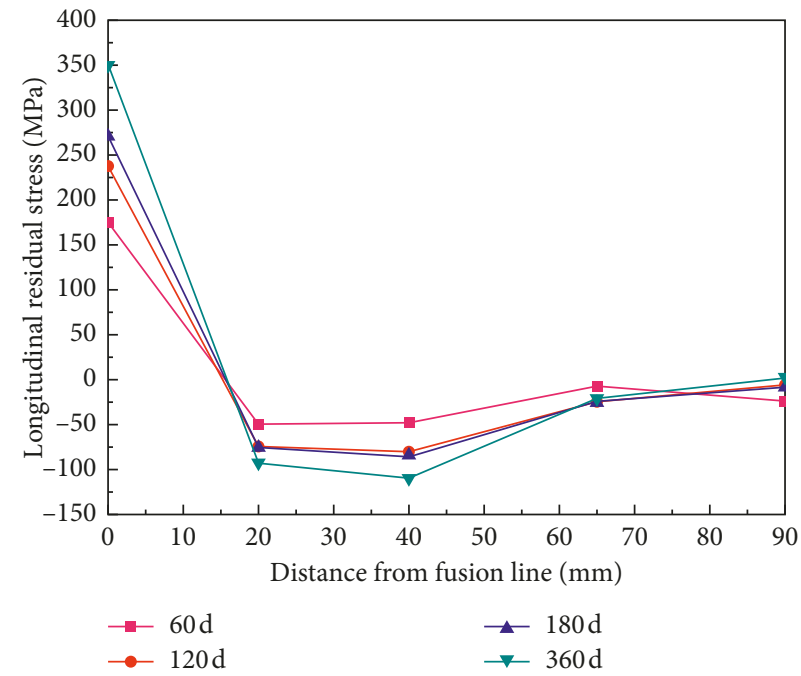

(b)

FIGURE 8: Evolution law of longitudinal residual stress distribution. (a) Welded structure processed by VSR. (b) Welded structure unprocessed by VSR.

evolution law of corrosion grooves' depth in the fusion line, whose increasing rate decreases with corrosion time increases. It can be inferred that corrosion damages in the fusion line of the welded structure can effectively increase residual stress in the fusion line and serve as an important factor in influencing residual stress in the fusion line.

The evolution law of comprehensive residual stress distribution on the surface of the welded structure is shown in Figure 9. The comprehensive residual stress is tensile stress on the surface of the welded structure, and the peak point of comprehensive residual stress is located in the fusion line. As the distance from the fusion line grows, comprehensive residual stress on the surface of the welded structure gets weaker. When corrosion time grows, comprehensive residual stress on the surface of the welded structure gets stronger. Furthermore, comprehensive residual stress in the fusion line rises most stably. This shows that although energies such as bond energy in structures dissipate into the environment through electrochemical reactions in corrosion, part of the surface energy can be converted into internal energy due to changes of corrosion morphology on the surface of the structure. Thus, comprehensive residual stress on the surface of the welded structure is increased at last. 


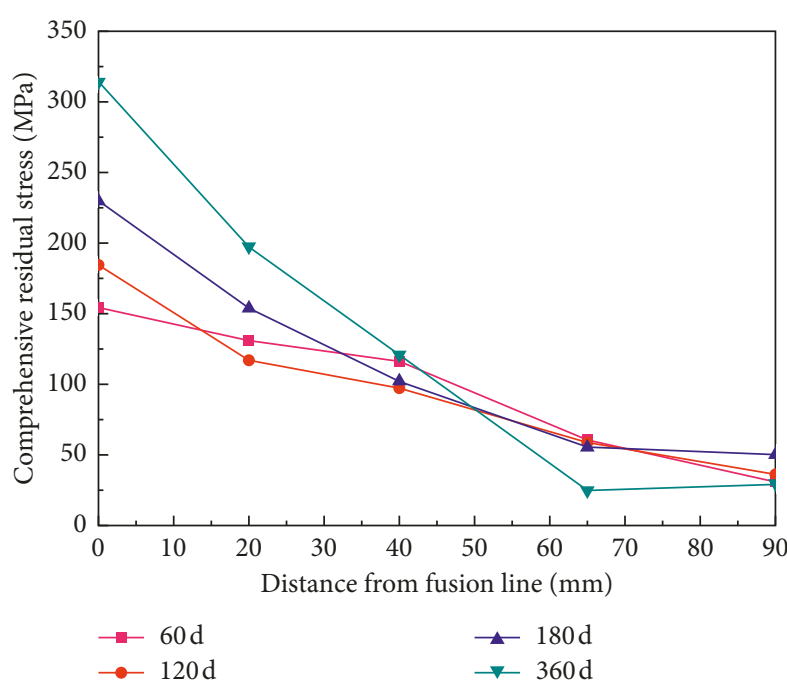

(a)

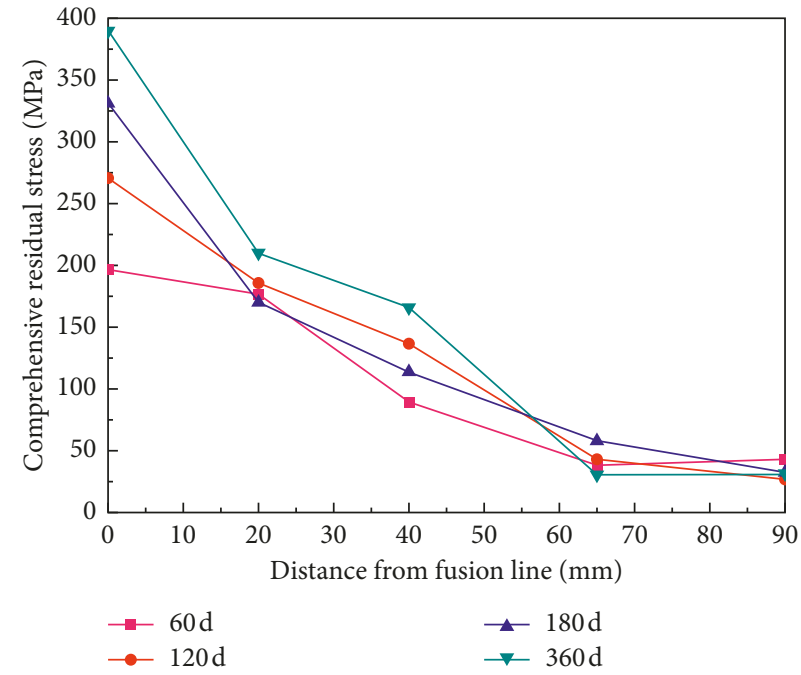

(b)

FIGURE 9: Evolution law of comprehensive residual stress distribution. (a) Welded structure processed by VSR. (b) Welded structure unprocessed by VSR.

When the welded structure is being corroded, residual stress and corrosion both not only contribute to the initiation of corrosion cracking in a welded structure but also contribute to each other's progress. On one hand, residual stress accelerates corroded damaging of the welded structure, and on the other hand, more corrosion damage leads to greater residual stress on the surface of the structure. Therefore, initiation of corrosion cracking of the welded structure is further accelerated.

3.4. Detection of Magnetic Field Distribution. To ensure the initial surface of corrosion specimens is intact, magnetic field distribution needed to be carried out before residual stress was detected. Detection results of magnetic field distribution on the corroded surface of welded structures processed and unprocessed by VSR are shown in Figure 10. Among them, $\mathrm{Hp}-1, \mathrm{Hp}-3, \mathrm{Hp}-5$, and Hp-7 are tangential components of magnetic field leakage in each channel and Hp-2, Hp-4, Hp-6, and Hp-8 are normal components of magnetic field leakage in each channel. Furthermore, weld center position is $x=120 \mathrm{~mm}$. The corroded damaging area on the surface of structure is decided by magnetic field leakage characteristic curve: the peak point of the tangential component in leakage magnetic field is located in the corrosion damage center, and magnetic field curve of the normal component in the corrosion damage center passes the zero point (as shown in Figure 11). For the welded structure processed by VSR, corroded magnetic field leakage characteristic curve on the surface always appears within the area $20 \mathrm{~mm}$ from the weld center (Figure 10(a)). Thus, although welded structures have been processed by VSR, generation of severe corrosion damage still occurs, resulting from a coarse microstructure near the weld joint. However, in the areas whose distance is more than $20 \mathrm{~mm}$ away from the weld center, magnetic field leakage characteristic curve never occurs. This means that serious corrosion damage does not appear in areas far away from the weld center after the welded structure is processed by VSR. However, obvious magnetic flux leakage is detected in all parts of the corroded surface of the welded structure unprocessed by VSR (Figure 10(b)). Therefore, under the influences of residual stress and corrosion, serious corrosion damage not only generates in areas near the weld joint but also appears in areas far away from the weld center due to galvanic corrosion accelerated by residual stress.

While analyzing the magnetic memory signal of a metal structure, the extent of corrosion damage on the metal surface can be effectively measured with changes of magnetic field gradient: the greater the changes of magnetic field gradient are, the more serious the corrosion damage is [39, 40]. Evolution laws of three-dimensional surface magnetic field gradient distribution of both welded structures processed and unprocessed by VSR are shown in Figure 12. The darker the color is, the greater the changes in magnetic field gradient are. It is found that corrosion damages in the areas near the weld joint of the welded structure processed by VSR are heavier than damages in other regions (Figure 12(a)). For the welded structure unprocessed by VSR, corrosion damage on different parts of the surface sees no obvious laws in the early days of corrosion $(60 \mathrm{~d})$. However, as corrosion time increases, the most seriously damaged areas gradually transfer to the weld joint. When corrosion time is $360 \mathrm{~d}$, the most seriously damaged areas are fully along the weld joint and parallel to the weld joint direction (Figure 12(b)).

Thus, under the influences of microstructure, residual stress, and corrosion, corrosion damage near the weld joint of the welded structure will be more serious than the damage in other regions as the corrosion time increases. Then, continuous corrosion damages that are parallel to the direction of the weld joint will converge together, leading to the corrosion cracks that are parallel to the welding direction 

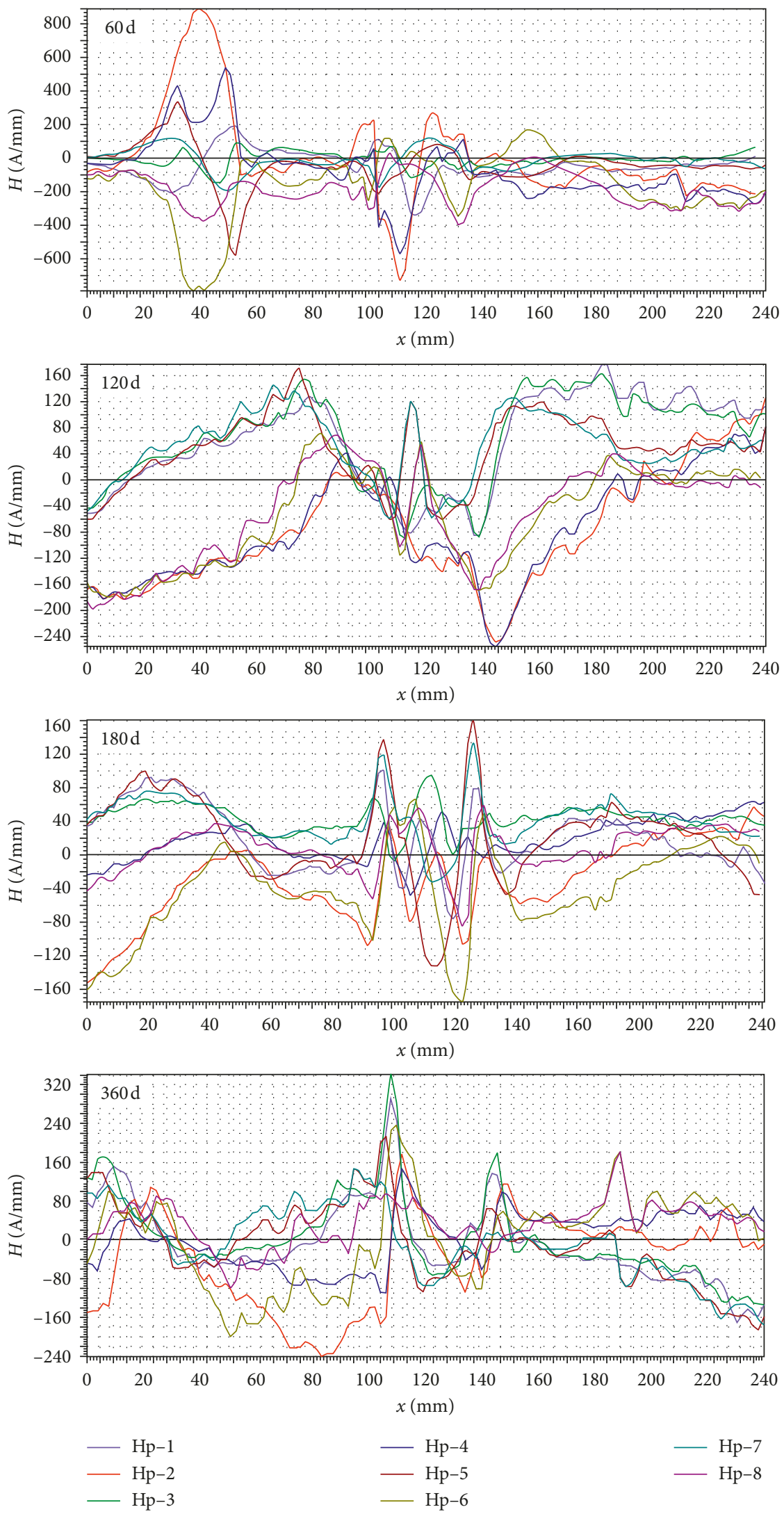

(a)

Figure 10: Continued. 

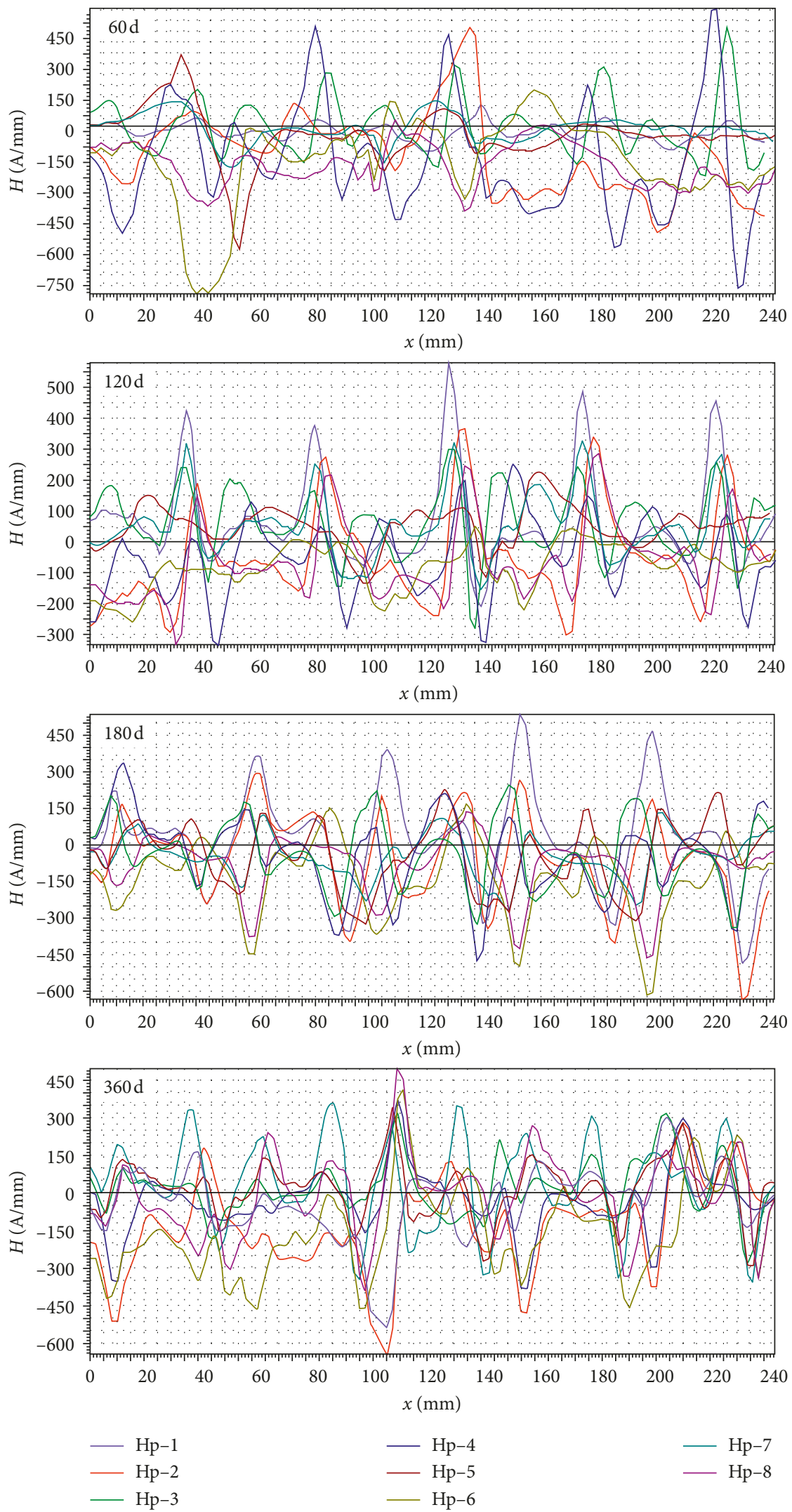

(b)

FIGURE 10: Evolution law of surface magnetic field distribution. (a) Welded structure processed by VSR. (b) Welded structure unprocessed by VSR. 


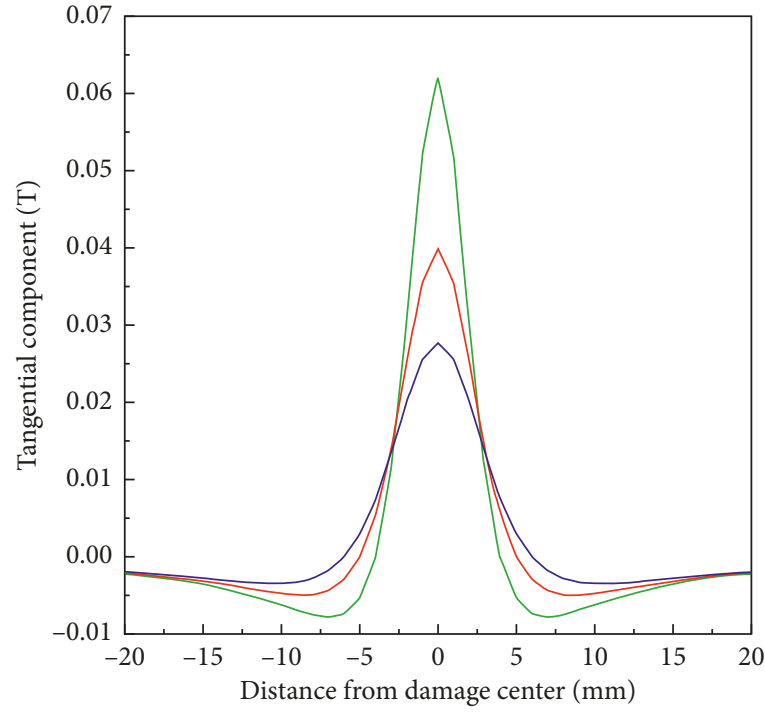

(a)

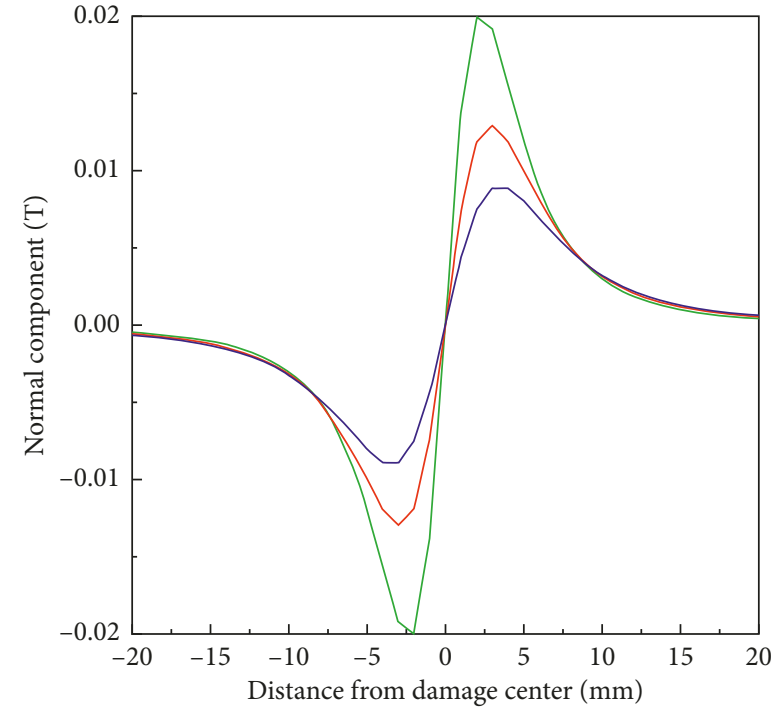

(b)

Figure 11: Leakage magnetic field characteristic curve.
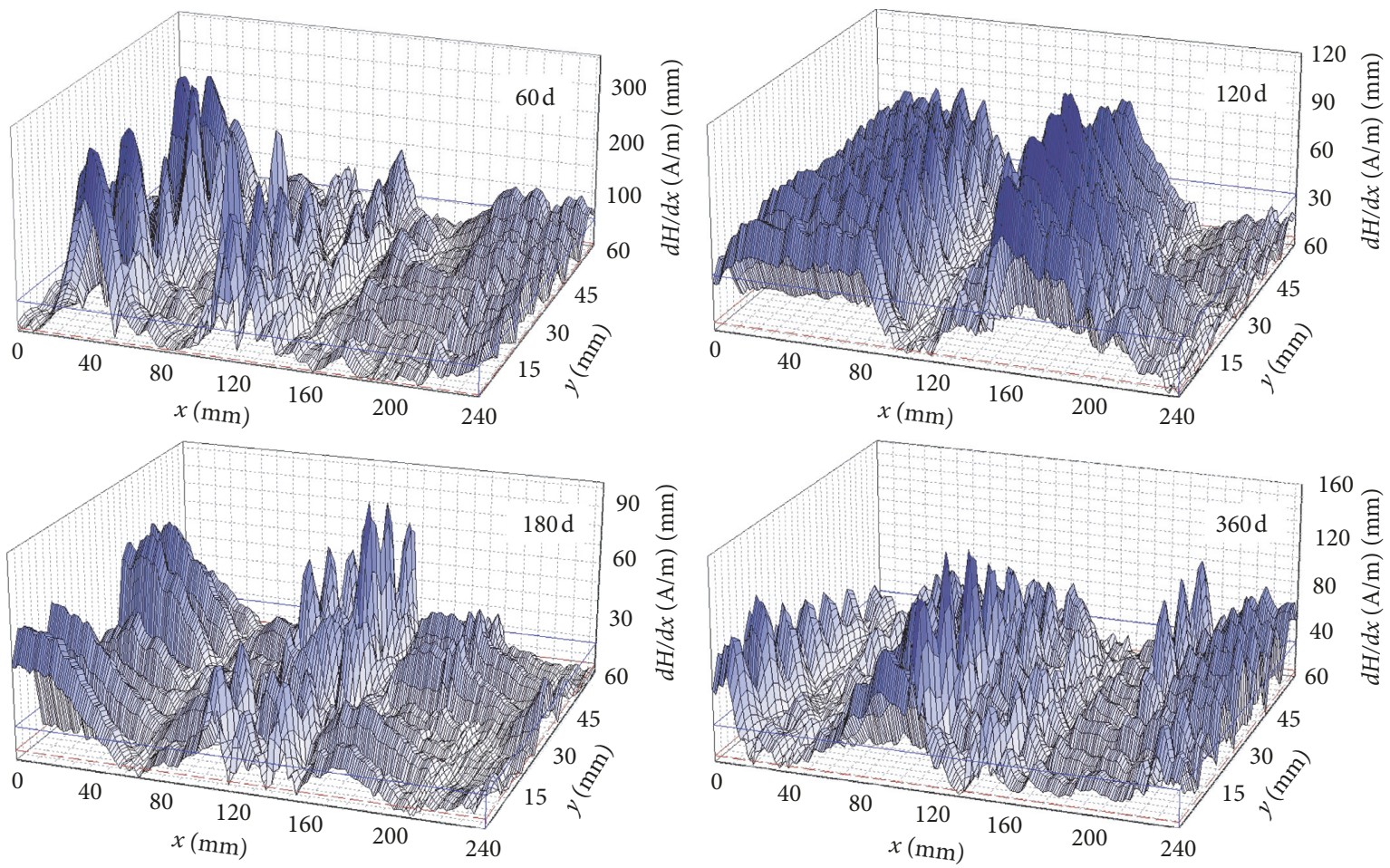

(a)

Figure 12: Continued. 

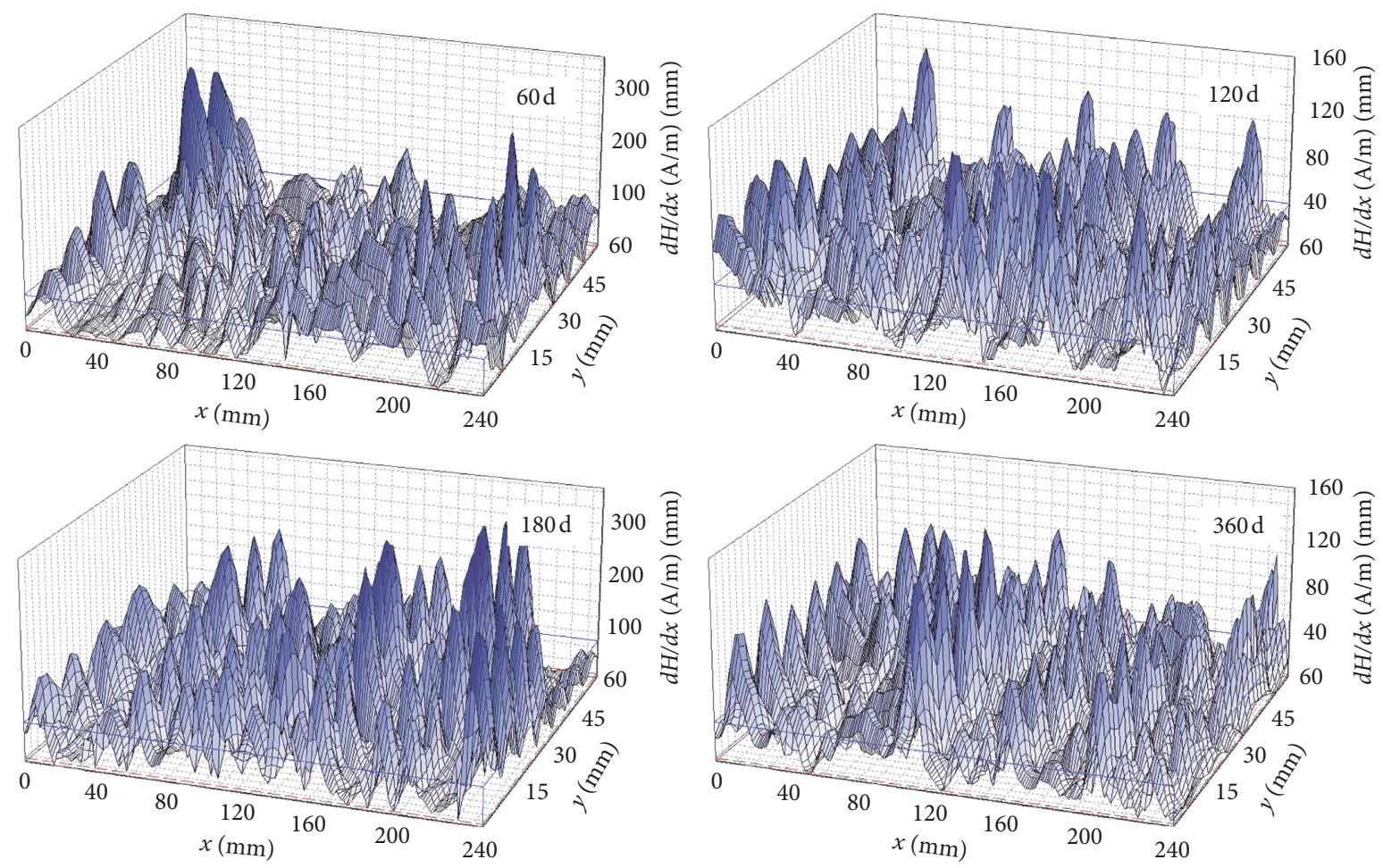

(b)

FIGURE 12: Evolution law of magnetic field gradient on surface of welded structure. (a) Welded structure processed by VSR. (b) Welded structure unprocessed by VSR.

first generated near the weld joint. Determined by the observation of corrosion morphology (Figure 5) in the fusion line, corrosion cracks near the weld joint first generate in the fusion line.

\section{Conclusions}

In this paper, evolution laws of surface corrosion morphology, residual stress, and areas with the most serious corrosion damage in corroded welded structures in natural seawater are studied. Furthermore, corrosion crack nucleation mechanism of welded structures in natural seawater is revealed by microstructure observation and the conclusions are as follows:

(1) While serving in natural seawater, microstructures of the weld joint, HAZ, and the fusion line are the main factors in determining surface corrosion morphologies and evolution process in all areas.

(2) Compared to the weld joint and HAZ, areas with the most serious corrosion damage generate in the fusion line at last. Additionally, continuous corrosion grooves are formed, which are caused by two aspects: one is the difference of corrosion rates between the weld joint and HAZ near the fusion line, the other is the coarse Widmanstätten structure in the fusion line.

(3) On one hand, residual stress in the welded structure speeds up the generation of corrosion damage on the surface of the structure; on the other hand, the development of corrosion damage in turn increases the level of residual stress. Thus, nucleation of corrosion cracks is further accelerated by the mutual promotion between residual stress and corrosion damages.

(4) Under the influences of microstructure, residual stress, and corrosion, areas with the most serious corrosion damage will generate in the fusion line as corrosion time increases. Finally, as several serious corrosion damages get together, corrosion cracks parallel to the welding direction first generate in the fusion line, making welded structures the origin of corrosion failure in marine steel structures.

\section{Data Availability}

The data used to support the findings of this study are included within the article.

\section{Conflicts of Interest}

The authors declare that there are no conflicts of interest regarding the publication of this paper.

\section{Acknowledgments}

The authors wish to acknowledge the financial supports from the project of the Major State Basic Research Development 
of China (973 Program, no. 2014CB046801) and China Postdoctoral Science Foundation (Grant no. 2017M623403).

\section{References}

[1] H. Polezhayeva, A. I. Toumpis, A. M. Galloway, L. Molter, B. Ahmad, and M. E. Fitzpatrick, "Fatigue performance of friction stir welded marine grade steel," International Journal of Fatigue, vol. 81, pp. 162-170, 2015.

[2] H. X. Wang, C. W. Du, Z. Y. Liu, D. D. Song, and X. G. Li, "The effect of hydrogen on stress corrosion behavior of X65 steel welded joint in simulated deep sea environment," Ocean Engineering, vol. 114, pp. 216-223, 2016.

[3] B. Ahmad and M. E. Fitzpatrick, "Analysis of residual stresses in laser-shock-peened and shot-peened marine steel welds," Metallurgical and Materials Transactions A, vol. 48, no. 2, pp. 759-770, 2017.

[4] Q. Wang, X. Liu, W. Wang, C. Yang, X. Xiong, and H. Fang, "Mixed mode fatigue crack growth behavior of Ni-Cr-Mo-V high strength steel specimens," International Journal of $\mathrm{Fa}$ tigue, vol. 102, pp. 79-91, 2017.

[5] B. Sabbaghzadeh, R. Parvizi, A. Davoodi, and M. H. Moayed, "Corrosion evaluation of multi-pass welded nickel-aluminum bronze alloy in $3.5 \%$ sodium chloride solution: a restorative application of gas tungsten arc welding process," Materials and Design, vol. 58, pp. 346-356, 2014.

[6] B. Ahmad and M. E. Fitzpatrick, "Effect of ultrasonic peening and accelerated corrosion exposure on the residual stress distribution in welded marine steel," Metallurgical and Materials Transactions A, vol. 46, no. 3, pp. 1214-1226, 2015.

[7] M. A. Garcia-Renteria, V. H. Lopez-Morelos, J. GonzalezSanchez, R. Garcia-Hernandez, L. Dzib-Perez, and F. F. Curiel-Lopez, "Effect of electromagnetic interaction during fusion welding of AISI 2205 duplex stainless steel on the corrosion resistance," Applied Surface Science, vol. 396, pp. 1187-1200, 2017.

[8] S. Li, H. G. Dong, L. Shi, P. Li, and F. Ye, "Corrosion behavior and mechanical properties of $\mathrm{Al}-\mathrm{Zn}-\mathrm{Mg}$ aluminum alloy weld," Corrosion Science, vol. 123, pp. 243-255, 2017.

[9] J. Jelovica, J. Romanoff, S. Ehlers, and J. Aromaa, "Ultimate strength of corroded web-core sandwich beams," Marine Structures, vol. 31, pp. 1-14, 2013.

[10] S. Krebs, F. Gaertner, and T. Klassen, "Cold spraying of $\mathrm{Cu}-$ Al-Bronze for cavitation protection in marine environments," Materialwissenschaft und Werkstofftechnikt, vol. 45, no. 8, pp. 708-716, 2014.

[11] S. Paul, Q. Lu, and M. D. F. Harvey, "Mitigating localized corrosion using thermally sprayed aluminum (TSA) coatings on welded 25\% Cr superduplex stainless steel," Journal of Thermal Spray Technology, vol. 24, no. 4, pp. 629-636, 2015.

[12] O. Adedipe, F. Brennan, and A. Kolios, "Review of corrosion fatigue in offshore structures: present status and challenges in the offshore wind sector," Renewable and Sustainable Energy Reviews, vol. 61, pp. 141-154, 2016.

[13] J. Tuominen, J. Nakki, H. Pajukoski, J. Miettinen, T. Peltola, and P. Vuoristo, "Wear and corrosion resistant laser coatings for hydraulic piston rods," Journal of Laser Applications, vol. 27, no. 2, pp. 1-12, 2015.

[14] X. F. Liao, L. B. Zhang, J. H. Peng et al., "Carbothermic reduction of marine placer with additional aluminum," Powder Technology, vol. 311, pp. 34-40, 2017.

[15] T. Hu, X. F. Liao, J. Li et al., "Preparation of coating material of welding electrode from marine placer via carbothermic reduction,” ISIJ International, vol. 57, no. 9, pp. 1603-1608, 2017.

[16] M. M. Ma, F. Lian, L. P. Zang, Q. K. Xiang, and H. C. Zhang, "Effect of dimple depth on friction properties of aluminum alloy under different lubrication conditions," Acta Metallurgia Sinica, vol. 53, no. 4, pp. 406-414, 2017.

[17] P. Hu, R. Song, J. Deng et al., "Electrochemical corrosion behavior of platinum-coated lanthanum doped titaniumzirconium-molybdenum alloy," Journal of Alloys and Compounds, vol. 706, pp. 305-311, 2017.

[18] Q. Qiao, G. X. Cheng, Y. Li, W. Wu, H. J. Hu, and H. Huang, "Corrosion failure analyses of an elbow and an elbow-to-pipe weld in a natural gas gathering pipeline," Engineering Failure Analysis, vol. 82, pp. 599-616, 2017.

[19] J. Kangazian, M. Shamanian, and A. Ashrafi, "Dissimilar welding between SAF 2507 stainless steel and Incoloy $825 \mathrm{Ni}$ based alloy: the role of microstructure on corrosion behavior of the weld metals," Journal of Manufacturing Processes, vol. 29, pp. 376-388, 2017.

[20] B. Han, Y. B. Chen, W. Tao, H. Li, and L. Q. Li, "Microstructural evolution and interfacial crack corrosion behavior of double-sided laser beam welded 2060/2099 Al-Li alloys T-joints," Materials \& Design, vol. 135, pp. 353-365, 2017.

[21] M. Azhideh, H. Aghajani, and H. Pourbagheri, "Surface characterization and corrosion resistance of 36Cr-Ni-Mo4 steel coated by WC-Co cermet electrode using microelectro welding," Metals, vol. 7, no. 8, p. 308, 2017.

[22] Y. B. Shang, H. J. Shi, Z. X. Wang, and G. D. Zhang, "In-situ SEM study of short fatigue crack propagation behavior in a dissimilar metal welded joint of nuclear power plant," Materials and Design, vol. 88, pp. 598-609, 2015.

[23] L. Wang, L. Hui, S. Zhou, L. Xu, and B. He, "Effect of corrosive environment on fatigue property and crack propagation behavior of Al 2024 friction stir weld," Transactions of Nonferrous Metals Society of China, vol. 26, no. 11, pp. 2830-2837, 2016.

[24] Z. Y. Jie, Y. D. Li, and X. Wei, “A study of fatigue crack growth from artificial corrosion pits at welded joints under complex stress fields," Fatigue \& Fracture of Engineering Materials \& Structures, vol. 40, no. 9, pp. 1364-1377, 2017.

[25] A. Swierczynska, J. Labanowski, J. Michalska, and D. Fydrych, "Corrosion behavior of hydrogen charged super duplex stainless steel welded joints," Materials and Corrosion, vol. 68, no. 10, pp. 1037-1045, 2017.

[26] Z. K. Zhang, Y. Yu, J. F. Zhang, and X. J. Wang, "Corrosion behavior of keyhole-free friction stir spot welded joints of dissimilar 6082 aluminum alloy and DP600 galvanized steel in 3.5\% NaCl solution," Metals, vol. 7, no. 9, p. 338, 2017.

[27] N. Li, W. Y. Li, X. W. Yang, and N. D. Alexopoulos, "Corrosion performance and mechanical properties of friction stir welded AA2024-T3 joints under different corrosion solution exposure," Materials and Corrosion, vol. 68, no. 9, pp. 970976, 2017.

[28] G. Schmitt, L. Sobbe, and W. Bruckhoff, "Corrosion and hydrogen-induced cracking of pipeline steel in moist triethylene glycol diluted with liquid hydrogen sulfide," Corrosion Science, vol. 27, no. 10-11, pp. 1071-1076, 1987.

[29] C. H. Shen and P. G. Shewmon, "A mechanism for hydrogeninduced intergranular stress corrosion cracking in alloy 600," Metallurgical Transactions A, vol. 21, no. 5, pp. 1261-1271, 1990.

[30] L. V. Ratych, "Contribution of anodic dissolution and hydrogen embrittlement to corrosion-fatigue crack growth," Materials Science, vol. 35, no. 3, pp. 310-325, 1999. 
[31] W. Y. Chu, L. J. Qiao, and K. W. Gao, "Investigation of stress corrosion cracking under anodic dissolution control," Chinese Science Bulletin, vol. 46, no. 9, pp. 717-722, 2001.

[32] A. Campanile, V. Piscopo, and A. Scamardella, "Incidence of residual stresses and steel properties variability on corroded bulk carrier reliability," Ocean Engineering, vol. 128, pp. 5880, 2016.

[33] Y. Savguira, T. H. North, and S. J. Thorpe, "Effect of grain size and residual stress on the corrosion resistance of friction stir spot welded AZ31B joints," Materials and Corrosion, vol. 67, no. 10, pp. 1068-1074, 2016.

[34] Y. Liu, S. W. Tang, G. Y. Liu, Y. Sun, and J. Hu, "Effect of residual stress relaxation by means of local rapid induction heating on stress corrosion cracking behavior and electrochemical characterization of welded Ti-6Al-4V alloy under slow strain rate test," Metals and Materials International, vol. 23, no. 3, pp. 488-498, 2017.

[35] O. Adedipe, F. Brennan, A. Mehmanparast, A. Kolios, and I. Tavares, "Corrosion fatigue crack growth mechanisms in offshore monopile steel specimens," Fatigue and Fracture of Engineering Materials \& Structures, vol. 40, no. 11, pp. 1868-1881, 2017.

[36] M. C. Sun, Y. H. Sun, and R. K. Wang, "Vibratory stress relieving of welded sheet steels of low alloy high strength steel," Materials Letters, vol. 58, no. 7-8, pp. 1396-1399, 2004.

[37] Z. Q. Zhu, L. G. Chen, and D. L. Rao, "Relieving welding residual stress by applying vibratory weld conditioning," Materials Science Forum, vol. 490-491, pp. 475-480, 2005.

[38] H. Y. Xing, Y. B. Dang, B. Wang, and J. C. Leng, "Quantitative metal magnetic memory reliability modeling for welded joints," Chinese Journal of Mechanical Engineering, vol. 29, no. 2, pp. 372-377, 2016.

[39] S. K. Ren, Y. C. Ou, and Y. Li, "Fatigue damage assessment for ferromagnetic items based on the metal magnetic memory technique," Insight-Non-Destructive Testing and Condition Monitoring, vol. 53, no. 9, pp. 494-496, 2011.

[40] A. Dubov and S. Kolokolnikov, "The metal magnetic memory method application for online monitoring of damage development in steel pipes and welded joints specimens," Welding in the World, vol. 57, no. 1, pp. 123-136, 2013. 


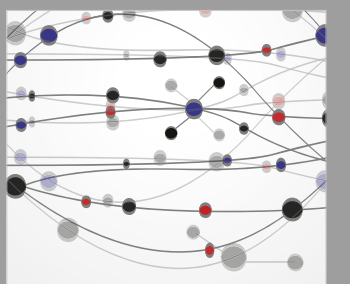

The Scientific World Journal
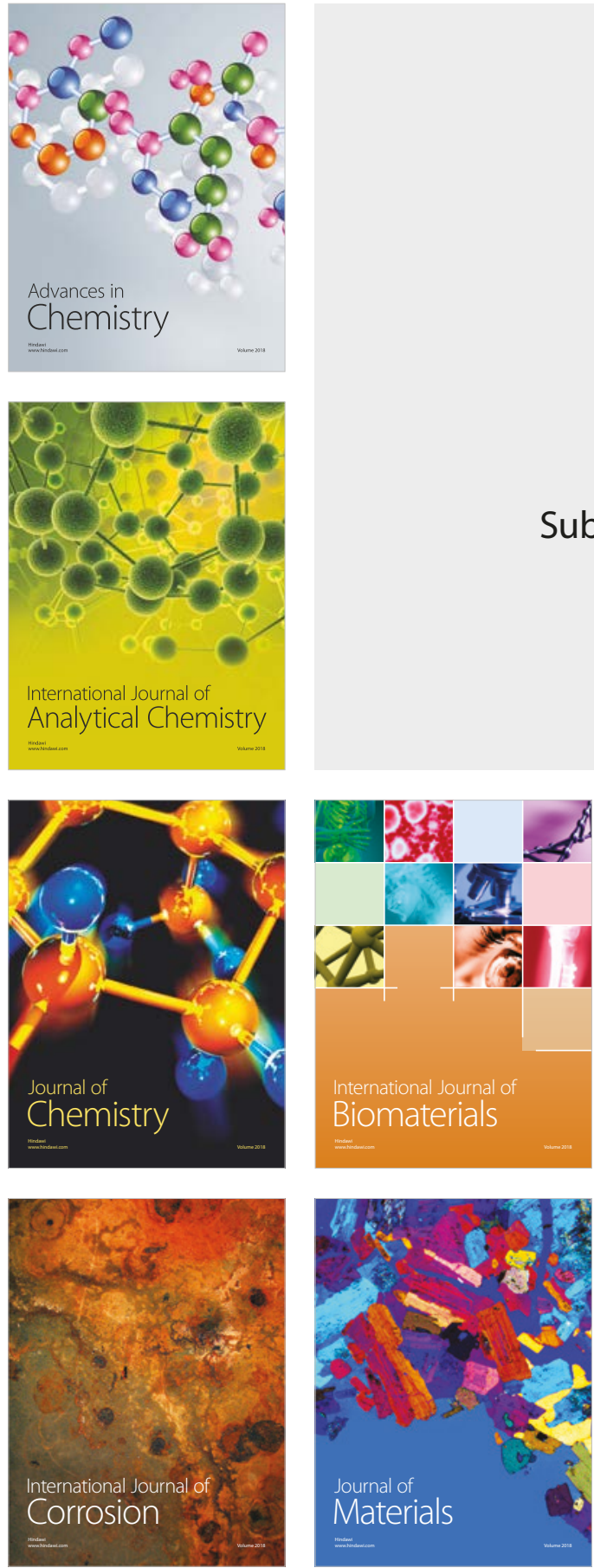

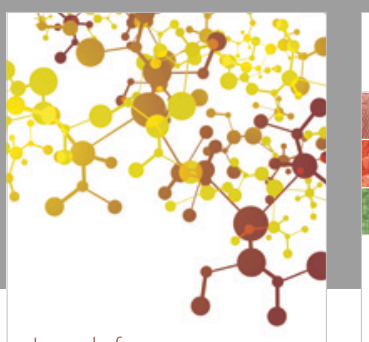

Journal of

Applied Chemistry
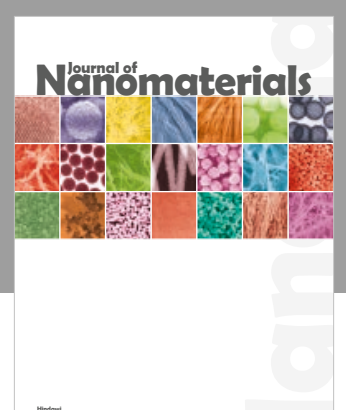

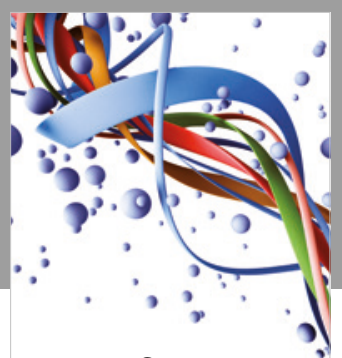

Scientifica

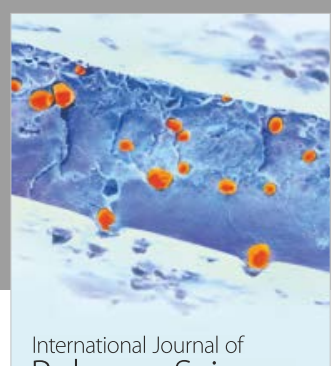

Polymer Science

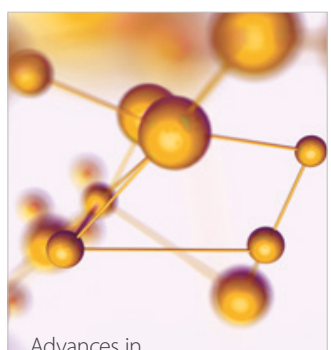

Physical Chemistry
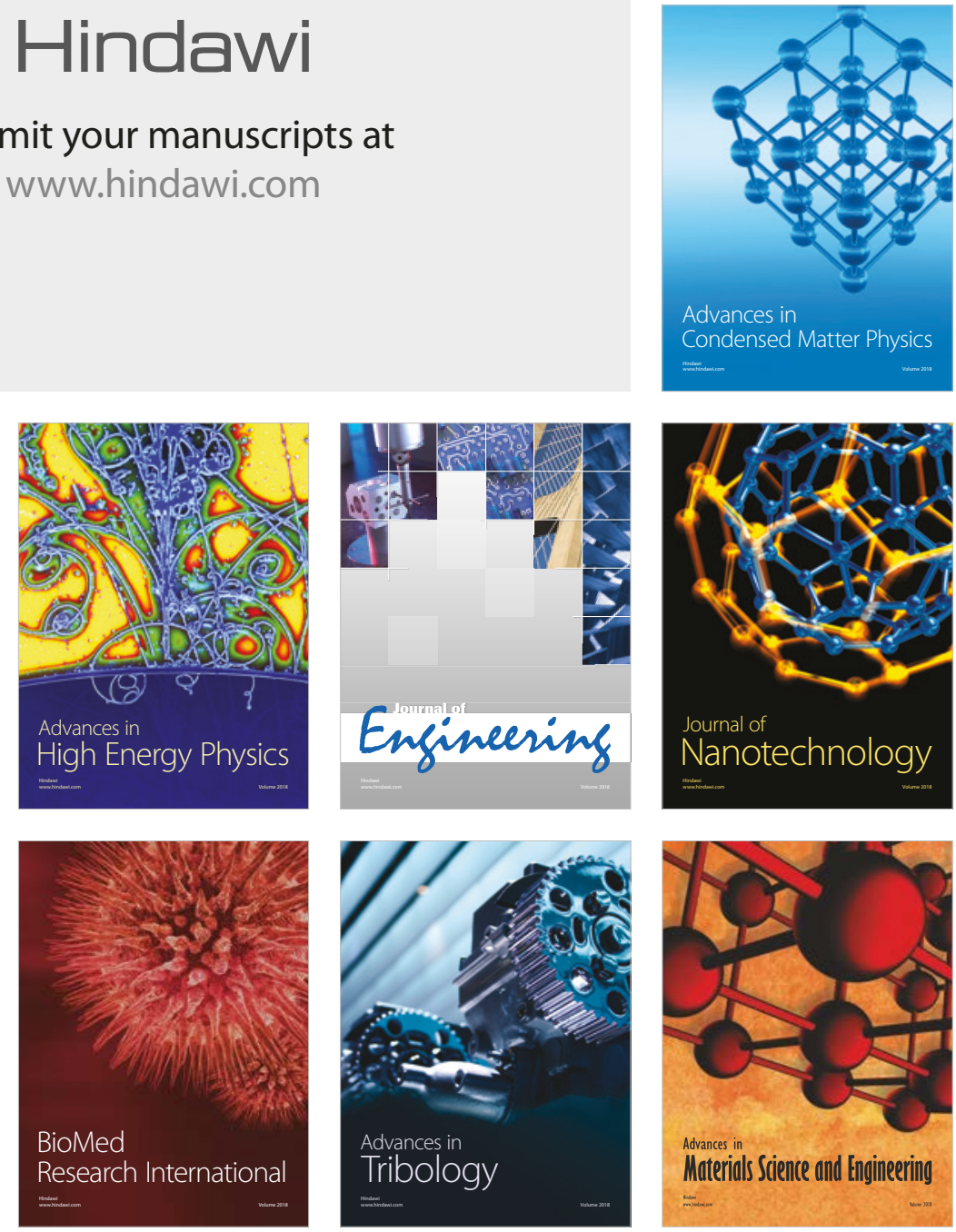